\title{
Congratulations to the Academician Xin-He Bao's team and the Academician Dong-Yuan Zhao's team for winning the first prizes of the State Natural Science Award of China
}

\author{
Miao Zhang* \\ Chemical Synthesis Editorial Office, Xi'an 710077, Shaanxi, China. \\ *Correspondence to: Miao Zhang, Chemical Synthesis Editorial Office, Suite 1504, Plaza A, Xi'an National Digital Publishing Base, \\ No. 996 Tiangu 7th Road, Gaoxin District, Xi'an 710077, Shaanxi, China. E-mail: editorialoffice@chesynjournal.com
}

How to cite this article: Zhang M. Congratulations to the Academician Xin-He Bao's team and the Academician Dong-Yuan Zhao's team for winning the first prizes of the State Natural Science Award of China. Chem Synth 2021;1:11.

https://dx.doi.org/10.20517/cs.2021.17

Received: 4 Nov 2021 Accepted: 4 Nov 2021 Published: 4 Nov 2021

Academic Editor: Bao-Lian Su Copy Editor: Xi-Jun Chen Production Editor: Xi-Jun Chen

On November 3, 2021, the 2020 State Science and Technology Award Conference was held at the Great Hall of the People in Beijing, China.

Among the five State Science and Technology Awards, the State Natural Science Award is conferred on Chinese citizens who have made major scientific discoveries in clarifying natural phenomena, characteristics and rules in fundamental research and applied fundamental research.

The two first prizes of the State Natural Science Award in 2020 are all won by research results in the field of chemistry. The team of Academician Xin-He Bao [Figure 1] from Dalian Institute of Chemical Physics, Chinese Academy of Sciences, and the team of Academician Dong-Yuan Zhao [Figure 2] from Fudan University both won the award.

The Academician Xin-He Bao's team proposed the new concept of "nano-confined catalysis" and successfully realized the direct and efficient synthesis of light olefins and high-value chemicals from coalsynthesized gas. It overturned the Fischer-Tropsch Synthesis process, which has dominated the coal 


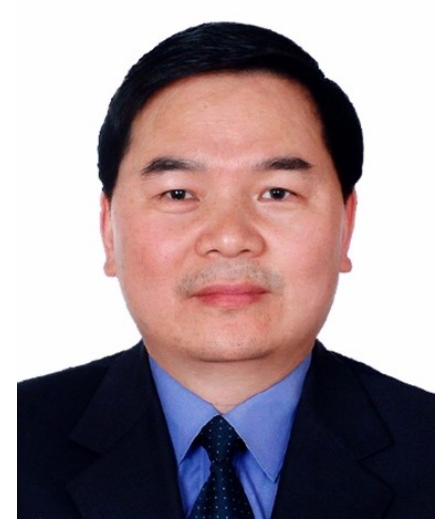

Figure 1. Academician Xin-He Bao (Image source: https://www.ustc.edu.cn/info/1007/6941.htm).

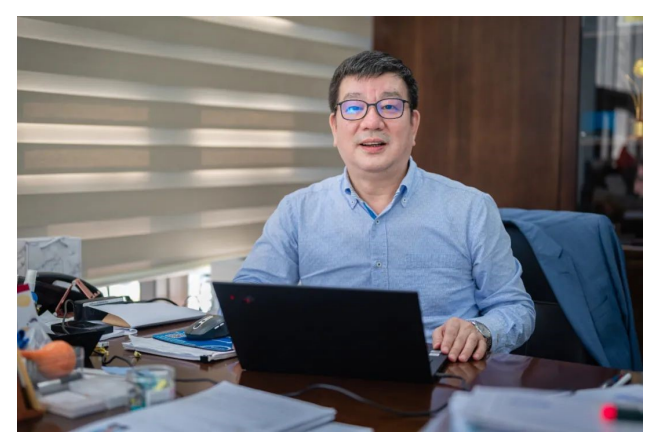

Figure 2. Academician Dong-Yuan Zhao (Image source: http://www.mesogroup.fudan.edu.cn/main.htm).

chemistry for nearly a century, leading the new trend of efficient and water-saving coal chemistry, laying a theoretical foundation for the "precision" of the catalytic process and catalyst design, and promoting the development of the catalysis discipline.

The team led by the Academician Dong-Yuan Zhao also won the award for the production and application of ordered mesoporous polymers and carbon materials. They are the first to put forward the idea of organic-organic self-assembled soft template synthesis of mesoporous materials in the world, which is the first time to expand functional mesoporous materials from inorganic frameworks to organic polymer materials, leading the development of the international mesoporous materials field.

Chemical Synthesis congratulates the team of Academician Xin-He Bao and the team of Academician DongYuan Zhao. We also hope there will be more original research results in the chemistry field to solve important scientific problems in basic research and people's livelihood. Chemical Synthesis will also commit to publishing original research in the field of chemistry continuously, aiming to become the premier resource of seminal and insightful research and showcases for researchers in both academia and industry, and providing a platform of inspiration for the future of chemistry.

\section{DECLARATIONS}

\section{Authors' contributions}

The author contributed solely to the article. 
Availability of data and materials

Not applicable.

Financial support and sponsorship

None.

\section{Conflicts of interest}

The author declared that there are no conflicts of interest.

\section{Ethical approval and consent to participate}

Not applicable.

\section{Consent for publication}

Not applicable.

\section{Copyright}

(c) The Author(s) 2021. 